\title{
form
}

https://doi.org/10.7577/formakademisk.3383

\author{
Rosamund Mosse \\ Learning Experience Designer (MSc) \\ Nesta, UK \\ rosamund.mosse@nesta.org.uk
}

Vol 13, No 4 (2020)

Relating

Relating systens
Special issue

Lewis Muirhead

Principal Consultant (MSc)

Alternate Future Design, Canada

lewisjmuirhead@gmail.com

\section{The Art of Hosting Participatory Practices in Social Labs: Moving Beyond Participation to Deep Engagement}

\author{
A case study of the Economic Immigration Lab in New \\ Brunswick, Canada
}

\begin{abstract}
Working with diverse groups to address complex issues is the primary aim of the burgeoning field of social labs. This paper investigates how the Art of Hosting $(\mathrm{AoH})$ helped the facilitation team at New Brunswick's Social and Public Innovation Lab (NouLAB) to build trust and integrate the wisdom of the participants into the lab process. We argue that AoH provided a container for the deep understanding and changes in perspective experienced by participants in the first two cycles of the lab. This study may be of use to those planning multi-stakeholder engagements and working in complex problem spaces.
\end{abstract}

Keywords:

Social innovation labs, Art of Hosting, participatory practices, public sector innovation, dialogic organizational development.

\section{INTRODUCTION}

Social innovation labs are inherently transdisciplinary. They borrow methods and tools from design thinking, systems thinking, participatory practice, policy development, human-centred design and more (Bason, 2014; Binder \& Brandt, 2008; Gryszkiewicz et al., 2016). Depending on the sector and focus, public sector innovation labs, i-labs or social labs are forums for multi-stakeholder engagement and have gained popularity worldwide as a way to deal with complex and intractable problems (McGann et al., 2018; Tonurist et al., 2015, 2017; Westley et al., 2015). Lab methodologies vary and are highly dependent on the skills and experiences of the individuals running them. This, combined with the diversity of participants, will elicit different outcomes based on the personalities, worldviews and experiences of those involved (Van der Merwe et al., 2019). 
At their core, these labs are experimental, multi-sectoral and systemic (Hassan, 2014) and happen through facilitated participatory engagements. Although work has been done to build a codified guide for their facilitation, only through experience and practice can facilitators build the skills necessary to guide stakeholders through a meaningful and fruitful co-creation process (Aguirre et al., 2017; Vorberg et al., 2014). While the tools from design-led practice have been adapted for policy creation (McGann et al., 2018), facilitators still require practices to guide and support their work to create the conditions that allow for enacting tangible change. We posit that the Art of Hosting and Harvesting Conversations that Matter (AoH) is an effective way to ingrain facilitators with the skills and abilities to practice dialogue, deliberation and co-creation in policy creation. The AoH practices a shift in the locus of direction and organization from facilitators to participants while providing tools to work in collaborative spaces, thus enabling and enhancing new relationships and ways of working.

The combination of AoH and social lab practices came together when convening the Economic Immigration Lab (EIL) in New Brunswick, Canada, which is ongoing at the time of this writing. The core facilitation teams are all experienced in $\mathrm{AoH}$ practices and apply the tools throughout the lab process to create the necessary conditions to work with a diversity of perspectives (Figure 1).

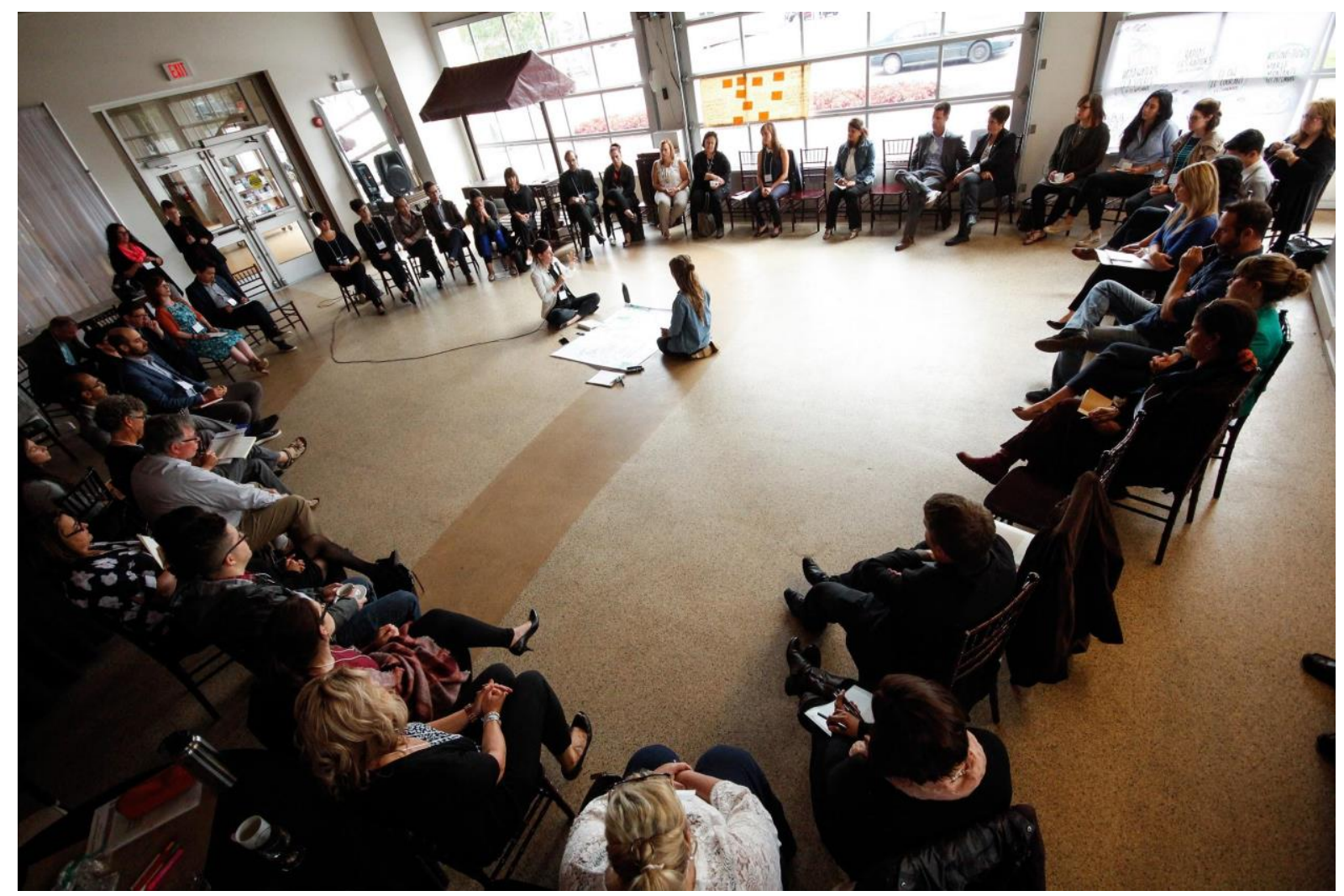

FIGURE 1. Exploring concepts in new ways: a conversation - aided by visuals - between facilitators (photograph: Jared Morrison, 2017)

\section{THE ECONOMIC IMMIGRATION LAB: A RESPONSE TO THE IMMIGRATION CHALLENGE IN NEW BRUNSWICK}

The EIL began in the fall of 2017 with a gathering of 34 stakeholders who shared an interest in the future of immigration in the province of New Brunswick. The EIL is structured as a social innovation lab, a process that has gained popularity as a forum for multi-stakeholder engagement and as a way to develop policy approaches in situations deemed as complex, wicked and (thus far) unsolvable (McGann et al., 2018; Tonurist et al., 2015, 2017; Westley et al., 2015). 
The EIL was born of a need identified by the New Brunswick Multicultural Council, the New Brunswick Business Council and the Government of New Brunswick to address a lack of immigration and retention of immigrants in the province. Although New Brunswick's economic growth for 2018 was better than expected, labour shortages were expected to hamper growth in 2019 and 2020 (R. Jones, 2018; Muthukumaran, 2018). According to the New Brunswick government's population growth strategy, there will be 60,000 job openings between 2018 and 2023. Coupled with the expected 110,200 exits from the workforce before 2026, this has led the province looking to international immigration as a source of ready-to-hire workers (Government of New Brunswick, 2017; Public Policy Forum, 2018). In response to this, and in coordination with the Atlantic Immigration Pilot Program, the EIL was launched in September of 2017 as a crucible for ideas for sustainable results-oriented action to increase immigration to the province. NouLAB functions as an authorizing environment - a safe space to innovate and suggest novel approaches - for delving into the root causes of the immigration challenge and promoting working in a truly multi-sectoral fashion (Bason, 2014. Government policymakers, along with representatives from the private sector, non-profit sector, academia and immigrants to New Brunswick, make up the lab teams. This diversity has meant that teams have a better understanding of the systems within which their challenge exists as well as the perspectives of the people who experience it. This has resulted in new and deeper policy interventions that aim to address the root of the challenge rather than responding to the symptoms. Because newcomers to the province comprise $27 \%$ of the participants, newcomer perspectives and lived experience have influenced all of the prototypes that have come out of the lab.

To achieve a cross-section of business, government, non-profit, individual and academic participation in the lab, the organizing team needed buy in from participants, approval from managers and a communicable case for the value of this way of working. Consideration was given to ensuring participants represented a range of frontline workers, middle management and executive leadership positions. In the end, we achieved a mix of $27 \%$ newcomers, $30 \%$ government agencies, $28 \%$ non-profits and $16 \%$ private sector employers (Figure 2). We had two participants from academia, but both were counted as newcomers as they were also immigrants to New Brunswick.
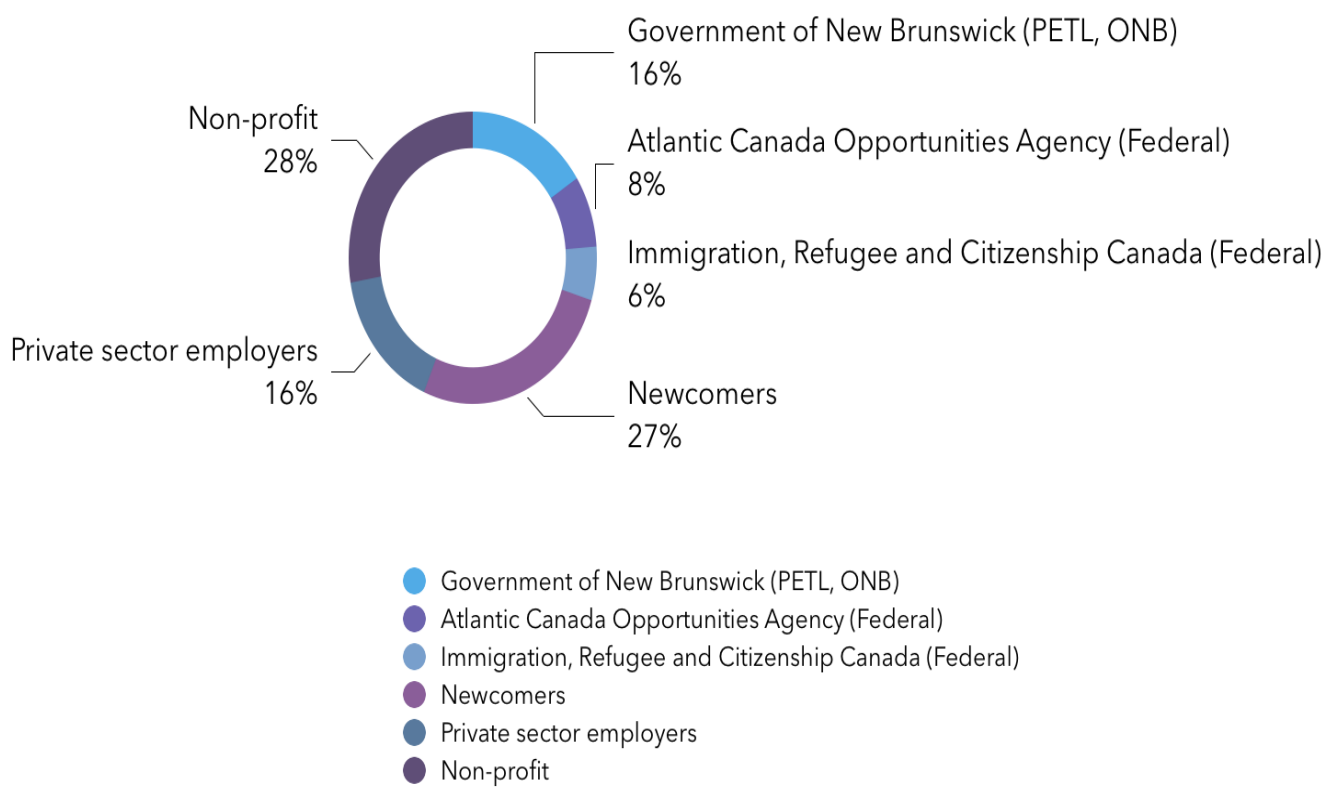

FIGURE 2. Sector breakdown of participants during the first two years of the EIL (Lewis Muirhead, 2018) 


\section{THE ART OF HOSTING AND HARVESTING CONVERSATIONS THAT MATTER}

The AoH is a network of practitioners and localised communities of practice. At the core of the $\mathrm{AoH}$ is a collection of participatory practices which enable groups to navigate complexity and create spaces for people to come together in different ways (Art of Hosting, 2019). These participatory practices are predicated on the idea that we collectively have the resources and wisdom to solve the complex challenges we face if we provide the time and space for that wisdom to emerge (Baldwin \& Linnea, 2010; Sandfort et al., 2012).

The AoH is built around four complementary and interconnected principles, together called the four-fold practice. To practice the art of hosting, first one must know how to host oneself in order to be present in the process. Second, one must be able to be hosted to participate in the process. Third, one must be able to host others to allow space for conversations to happen and others to participate. Fourth, one must be able to co-create with others to move from an individual learner to part of a community that learns (Transition US, 2013). Workshops in the AoH provide space and methods for individuals to practice all four elements of the four-fold practice.

The AoH assumes that our knowledge of and about the world is dependent on our position in society, and it places the practitioner within a larger community of practice that supports collaborative innovation and includes multiple actors in the design process (Bommert, 2010; Quick et al., 2012; Torfing, 2019). The AoH fosters a community of practice whereby practitioners actively support and share with one another. This is especially important because "systemic social innovation and transformation processes do not occur due to the activities of only a single leader or 'hero-preneur'; rather, it is through distributed agency" of stakeholders within the system (Moore et al., 2018, p. 1).

\section{LEARNING FROM EIGHTEEN MONTHS IN: HOW THE ART OF HOSTING HAS CONTRIBUTED TO NOULAB'S SOCIAL LAB PRACTICE}

The EIL was established as a three-year project. After 18 months and two cycles, this article was written to outline some of our findings. When looking at the change the EIL has helped foster in the immigration system in New Brunswick, our observations have led to a deceptively simple finding: systemic change happens at the level of relationships with the self and others. Through dialogue, action and reflection, these new relationships hold emergent potential for change that could not be foreseen. Both these relationships and their by-products (emergent change) ripple out into networks within the system, eventually resulting in a tipping point of systemic change (Lichtenstein, 2014). In other words, our theory of change is a combination of these two aphorisms: "The success of an intervention depends on the interior condition of the intervenor" (O'Brien, quoted in Scharmer \& Kauefer, 2010, pg. 18) and change only happens "as fast as the speed of trust" (Covey \& Merrill, 2006, pg. 2).

We are not alone in this conclusion. According to Drimie et al.'s (2018) experience of the Southern Africa Food Lab, "social innovations emerge from new ideas supported by new relationships and new commitments emerging from within transformative spaces that lead to action in the system" (p. 2). This was the case in the first cycle of the EIL, in which a month-long process of interviewing more than 70 applicants led to the selection of 34 participants from a diversity of sectors and lived experiences, who then self-organized into prototype teams around specific challenges within the context of economic immigration in New Brunswick.

We believe that it has been our training in and use of hosting practices that has allowed us to design and hold the space for systemic change, as described above, to emerge. The AoH has contributed to our social labs practice in two important ways: it has provided us with the theory and tools necessary to create a good container, and it is a toolkit of practices that encourages a collaborative, participatory and democratizing mindset.

\section{Creating a container}

The polarization of factious groups in any complex challenge means that simply applying design principles will not have the desired impact of creating systemic change. Instead, we need practices that help us to have conversations with one another, really listen to one another and enter into a co-creative 
state with one another. Therefore, bringing people into new types of relationship with themselves and each other encourages horizontal structures with inclusion, diversity, equity and access as their central pillars. This creates an intentional space for people to get in touch with their tacit or latent habits, mindsets and behaviours, which is just as important - if not more so - than the actual tools used (Nesta, 2019; Newman et al., 2014).

Creating a container is a term often used in the $\mathrm{AoH}$ community that means using the tenets of hosting to design how collaborative spaces might look, feel and operate. Imagine you invited someone over for a meal. You would endeavour to be welcoming in order to make them feel safe, comfortable and valued. You might set the scene with beautiful objects, art or candles. You would listen attentively to your guests, honour their boundaries and show them respect by behaving authentically and in allegiance with your values. Why, then, do we abandon these principles in the workplace?

In the case of the EIL, we believe the intentional work of creating the container made people feel welcome to share their thoughts and connect with others, sharing personal experiences and values rather than simply representing the perspectives of their employers. In order to achieve this container, the lab is held in spaces that are beautiful and accessible. We have a central stated purpose that invites people in, and we practice checking in while sitting in a circle (Baldwin \& Linnea, 2010). We spend a great deal of time up front getting to know one another as people outside of the work we are gathered to do. The practices of deep listening and guaranteeing equality of voices allows more room for details to emerge about individual experiences. Acknowledging the expertise, privilege and power in the room creates a space for understanding our unconscious biases. A good container demonstrates care for the community and ourselves. It means showing up as facilitators and modelling authenticity, vulnerability, comradeship and failure. As Chris Corrigan (2016), global steward of the $\mathrm{AoH}$, asserted:

For activities such as innovation in which groups are seeking newness and emergent practice, it is essential to host a dialogic container well. A good hosting practice helps to establish and support a container while allowing the emergent properties of such a structure to operate. (p. 32)

The outcomes of creating a good container can be difficult to measure, however. In the case of the EIL, $100 \%$ of the lab participants agreed or strongly agreed that they had the opportunity to collaborate with a compelling diversity of people (NouLAB, 2018). Good containers beget strong social fields, in which relationships between participants demonstrate trust, respect and creativity. Participants develop a sense of collective wellbeing and are able to understand a multiplicity of perspectives (Corrigan, 2015). In social labs, "this is a particularly important capacity for a group, since it allows for creativity to arise from diversity and for groups to be resilient and resourceful while confronting novel and confusing situations" (Corrigan, 2015, p. 294).

In the EIL, we noticed this establishment of the social field when policy creators came face to face with stakeholders of the problem they were working on - in some cases, for the first time. Government workers who were in charge of designing policy that impacted immigrants to New Brunswick were given the opportunity to converse with immigrants to New Brunswick and learn from their experiences in order to design a better policy collaboratively. Immigrants to the province were heard first hand about the limitations of the business and political structures and realised that the challenges they had faced when immigrating to New Brunswick were systemic rather than personal. When interviewed, $93 \%$ of the lab participants agreed that their understanding of both the newcomer and employer experience had improved, and $95 \%$ of participants were happy to have been able to analyze opportunities and barriers to immigrant attraction and retention within New Brunswick in order to prototype new paths forward (NouLAB, 2018).

Participants cited the atmosphere created by the hosting team, the encouragement to show up as their authentic selves, the opportunities to engage with people holding different perspectives on the issue and the space to reflect on how personal values and beliefs impact their vantage point and therefore understanding of the system as some of the most impactful components of the lab (NouLAB, 2018). Systemic change relies on those on either end of the power spectrum to develop a relationship with one another and, in so doing, begin to transform their understanding of the system as a whole, 
their part in it and the leverage available to them for action (Torfing, 2019). It would appear that the most meaningful and revolutionary aspect of the lab is in simply bringing folks with different lived experience, understandings of the challenge and capacities to interact with the system into conversation with one another. After all, "one cannot expect entire systems to radically shift if one cannot practice and embody a microversion of this in one's conversations with everyday colleagues" (Moore et al., 2018, p. 9).

As evidenced by its name, the Art of Hosting is a set of engagement tools to facilitate participatory and democratic conversation. It is ultimately an attempt to provide the best circumstances for dialogue to occur. "Dialogue is inherently relational" (Drimie et al., 2018, p. 2) and deepens relationships over time. At its most basic level, there is knowledge exchange, but methodologies that use dialogue build empathy and connections between participants, which contributes to their desire to find solutions that work for everyone (Senge et al., 2005). Corrigan (2016) expanded Brown and Isaacs's (2006) principle of creating a hospitable space to explain that containers created with the intention of facilitating dialogue are spaces

... in which dialogue occurs, specifically dialogue in which the results are unknown in advance and meaning, decisions, and strategy are emergent. This kind of dialogue is essential in any endeavour in which innovation or collective learning is to take place around complex and emergent issues. (p. 31)

AoH practices are designed to be customisable, responsive and emergent instead of being presented as best practices (Sandfort et al., 2012). As facilitators, we are working collaboratively, intuitively and with the expectation that the participants in our programs will co-create them with us. This is another principle from the $\mathrm{AoH}$, where "there are no explicit leaders who command authority; rather [a focus on] creating learning experiences" (Sandfort et al., 2012, p. 3). We check in with participants every day, ask them how they are doing and what they need. Their answers influence our design for the next day or the next few hours. We have thrown out plans because we learned that it was not what participants needed. In order to achieve the adaptability required to adjust on the fly and take feedback from participants, the hosting team has to regularly check in with each other. The team reflects on interactions they have had individually with participants and on comments made in plenary check-ins and check-outs. There is always an openness to recognise an issue or flag something that will inform a design adjustment. The nature of the conversations hosted in the EIL, where topics range from the future viability of companies to the cultural makeup of the province, have necessitated that we collectively address racism, the depiction of immigrants to the province as economic units and the challenge of working from a sense of purpose. Giving participants agency over their experience invites a new structure of working, where collective intelligence, self-organization, continuous adaptation and feedback coordination are possible through the readiness of hosts to make changes and assess situations in real time (P. Jones, 2014).

\section{Tools for co-creation and self-organization}

Some of the practices we use specifically enable participant agency. Open space technology, for example, is a process that encourages participants to self-organize to set the agenda, host conversations and gather insights to bring back to the collective (Owen, 2008). It gives participants a framework within which they can decide the direction that the collective process will take and relocate the power to fulfill their own needs and objectives for the session.

Circle practice - another tool for co-creation and self-organization - gives participants "an equal place, indicating that wisdom and leadership can come from anywhere" (Corrigan, 2015, p. 292). Circle practice is a deceptively simple methodology that can slow down the conversation and invite reflection and deep listening. Built around a shared purpose or intention, circle practice begins with an invitation. Participants are welcomed into the circle, within which is a physical centre (often some flowers, a candle, stones or other natural element). The group establishes agreements about how they will enter into relationship with one another, and a guardian of the circle is established to monitor time and energy or to call for a pause or silence as needed. The group might check in or speak straight to the 
purpose or intention depending on the type of council required. Similarly, the group might have several rounds to the circle, have a final check-out or simply close after everyone has had the opportunity to speak their mind (Baldwin \& Linnea, 2010).

Finally, a world café invites "collaborative dialogue around questions that matter in service to real work" (World Café Community Foundation, 2015). A world café situates nested conversations within larger conversations held together by a common question or theme. The process assumes that we are collectively more intelligent than we are as individuals and posits that conversations, when viewed as our main process of sharing collective knowledge, can shape the future we desire (World Café Community Foundation, 2015). There are seven design principles for hosting a world café: setting the context for the conversation; creating a hospitable, inclusive space; exploring questions that matter to the group; encouraging everyone's equal contribution; connecting a diversity of perspectives; listening together for emerging patterns and insights; and sharing collective discoveries back to the collective. The process invites small groups of people to participate in rounds of conversation predicated on progressing questions, with participants changing groups between rounds to cross-pollinate ideas and perspectives. World cafés end with a synthesizing and sensemaking of the collective patterns and discoveries in the room (World Café Community Foundation, 2015). A world café process allows participants agency in shaping collective discussions and facilitates the emergence of new knowledge from collective sensemaking in a way that feels structured and outcome focused, as insights are fed back into the collective understanding of the theme or question.

In the first cycle of the EIL, we opened with a world café that asked: When we invite people to live and work in New Brunswick, what are we inviting them into? What came out of this world café question was a churning up of some of the deep-seated racism in New Brunswick. It was an opportunity to discuss what it means to be a newcomer in New Brunswick, which was shocking for some. It became very apparent that the time allotted for these conversations was insufficient, and so the design was altered for the next day to include an open space technology session with the question: What conversations do we need to be having now?

During this session, participants took the opportunity to discuss the experience of being a newcomer through economic, cultural and gendered lenses. Observing the room, as shown in figure 3, the level of attention was palpable. Everyone was leaning in. These conversations were so important for creating authenticity and vulnerability to influence the prototypes that the group tackled and how members related to one another in the days and weeks to come. Because the facilitation team recognized the importance of being open and adaptive in our design, the topics of racism and the dehumanizing depiction of immigrants as economic units were brought to the surface and worked through. Furthermore, as a result of the facilitation team's ability to pivot, participants took away a more nuanced understanding of the socio-political elements of economic immigration. Facilitators heard from participants that this session directly impacted how they felt they could show up in the lab and resulted in at least two people choosing prototype topics and teams that they felt called to on a personal level as opposed to the ones that they might have joined because of an alignment with their employer or work. One prototype focused on increasing the availability of diversity education in public schools and another on increasing diversity in entry-level government jobs. These prototypes may not have emerged if we had not provided the space and time to explore some challenging topics in more depth. 


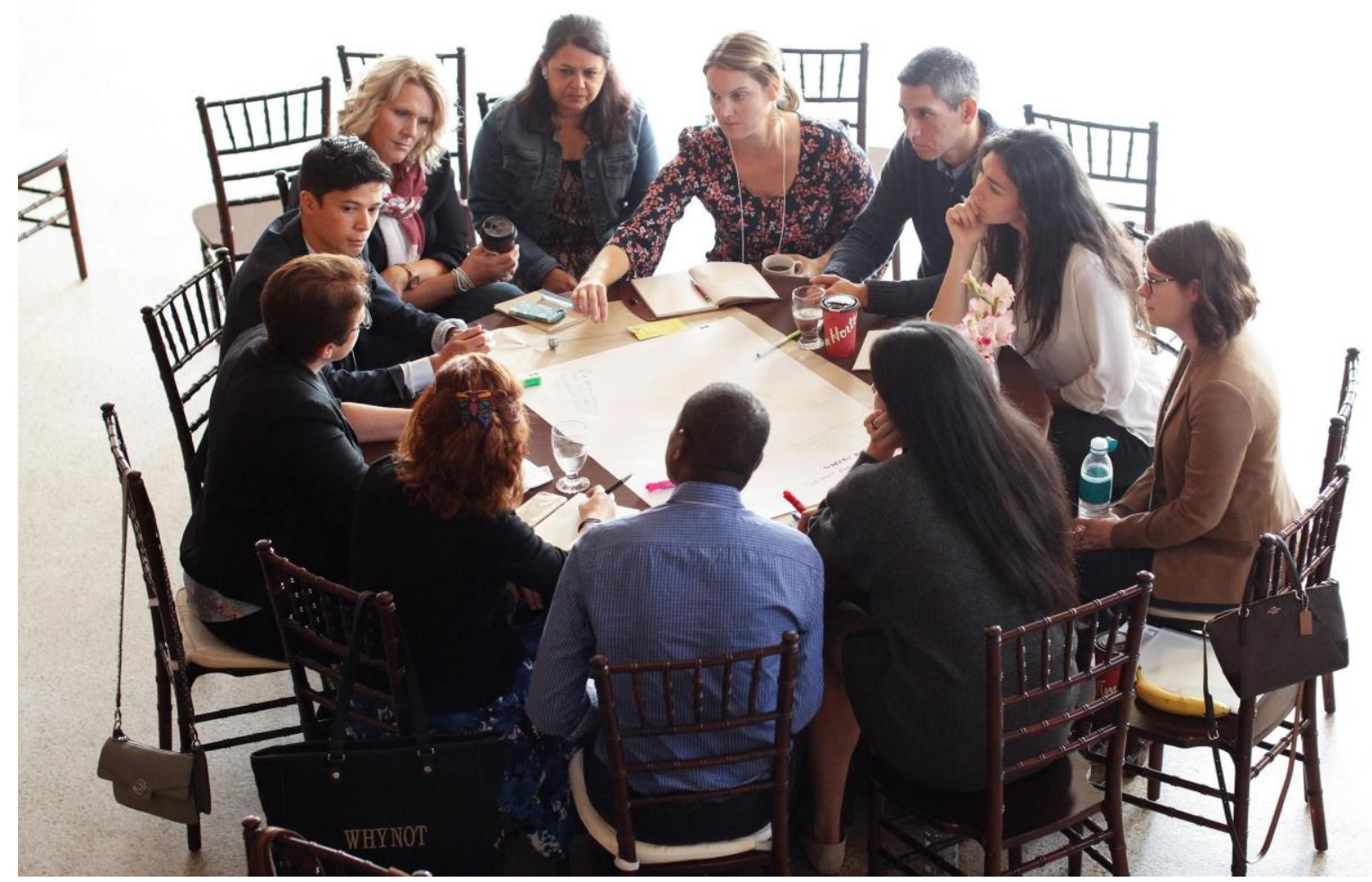

FIGURE 3. Working through challenging subjects in a circle to encourage an equal voice at the table (photograph: Jared Morrison, 2017)

Both the container and the principles of hosting played into how this scenario occurred the way it did. Firstly, both the world café and open space technology formats situated participants as the keepers and co-creators of knowledge, encouraged wide participation and disrupted the hierarchy of specialised knowledge. Indeed, the physical setup of these tools played a huge part in achieving these outcomes, effectively introducing "a level of disturbance to a group that helps them break out of entrained ways of thinking and invites them to think and work differently" (Corrigan, 2016. p. 34). Secondly, when the facilitators showed up in a different way, it broke the traditional, hierarchical power dynamic that exists - the one that gives certain people with certain voices more power than others. By sitting in a circle to collectively hear and resolve the issue, we invited everyone's perspectives equally. The EIL's success relied entirely on senior government officials - specifically at the Assistant Deputy Minister level - being willing to take the advice of non-traditional policymakers. Because of this willingness and the participation of the business community and immigration council at the strategic level, the people worth listening to - the experts on the ground - were able to have direct influence on policy development.

These practices not only serve in times of conflict but throughout the entire process. By addressing dynamics of identity, power and privilege, we are furthering our disruptive potential within social lab practices:

The invitation to participate in a community - of co-learners and co-producers of knowledge - also reflects hosting's distinctive and democratizing philosophies about deliberation and design, namely that all people in the room have wisdom, that deliberation enables the sharing of knowledge, that facilitators and others aim to decentre the authority of their position and expertise in the room and that participants coproduce deliberative policy processes as well as decisions. (Quick \& Sandfort, 2014, p. 317)

Indeed, this has been the case for one of the lab teams now prototyping a streamlined process to allow employers and potential employees to navigate the government services they need to meet the 
requirements for hiring and being hired in New Brunswick. Team members from Immigration, Refugees and Citizenship Canada (the national department for immigration in Canada), the department of PostSecondary Training, Education and Labour at the Government of New Brunswick, J. D. Irving Ltd. (the province's largest private employer) and Practical Human Resources Services Inc. came together across the national-provincial governmental divide, the public-private sector divide and with newcomers to the province in order to flesh out the immigration process as it is experienced by immigrants, employers wishing to hire immigrants and the governing institutions for immigration. Due to the design of the lab and the prominence of participatory practices as described above, each member of the team had equal voice and brought a needed perspective to the design of the prototype, even though a non-hierarchical way of working sometimes felt jarring.

Another team working on diversity in the government included senior government employees as well as students, and their coordination was imperative to building a new perspective on the issue. This prototype was ultimately expanded into an internal innovation team within the government of New Brunswick that integrated the findings of the lab team. Including the perspectives of students and building through multiple iterations resulted in a program that struck a strong enough chord with policymakers to ensure multi-year funding.

The structure of the lab also meant that teams received ample feedback from other participants in their cohort and tested their theories, assumptions and potential prototypes with those people who would ultimately end up using them. This broadened the scope and locus of knowledge production, relevant experience and the co-creative process.

\section{CONCLUSION}

The EIL turned out to be more than just a space to prototype solutions to the immigration challenges New Brunswick faces. By using AoH practices, the team at NouLAB managed to create a container which enabled participants to show up in their work and relationships to one another in new and deeper ways. Furthermore, we established a precedent for co-creation in the lab that gives participants agency over their experience and thus over the subsequent work and prototypes developed. We encouraged a transformation of identity, relationships and dynamics of power and privilege, thereby allowing for a change in the system that we believe would not have otherwise been possible. In our experience designing and facilitating the lab, the AoH provided a mindset, framework and set of practices to guide this process.

The $\mathrm{AoH}$ views individual values and belief systems as essential elements to work with in order to enact change. Similarly, in design literature, Valkenburg and Dorst (1998) also noted that the individual vantage point has as much influence on design as the context of the problem being addressed. Furthermore, Ryan's (2014) statement that "without reframing that shifts the thinking of individuals within design teams, except by accident, design projects will be incremental rather than transformational" (p. 4), echoes our observation that a true shift in the thinking of all individuals involved is key to making transformational change possible.

While not explicitly necessary to the design of social labs, we contend that the transformative experiences of coming together in conversation in new ways, reorganising traditional hierarchies into distributed horizontal leadership approaches and co-creating the structure and content of the lab with participants accounts for the performance and success of the EIL thus far. The methodologies and philosophy behind the $\mathrm{AoH}$ gave the facilitation team structure and guidance for designing and facilitating the lab in order to meet these ends.

\section{ACKNOWLEDGEMENTS}

This article has outlined some of our discoveries after 18 months of running the EIL. More than anything, we hope that it can serve as the start of a conversation with fellow practitioners, and we would be 
happy to hear from others in the field about their experiences and insights using participatory practices. Please feel free to reach out via the email addresses provided.

For more information on the EIL, please visit:

economicimmigrationlab.org and immigration.noulab.org 


\section{REFERENCES}

Aguirre, M., Agudelo, N., \& Romm, J. (2017). Design facilitation as emerging practice: Analyzing how designers support multi-stakeholder co-creation. She Ji: The Journal of Design, Economics, and Innovation, 3(3), 198-209. https://doi.org/10.1016/j.sheji.2017.11.003

Art of Hosting (AoH). (2019). What is the Art of Hosting?

Baldwin, C., \& Linnea, A. (2010). The circle way: A leader in every chair. Berrett-Koehler Publishers.

Bason, C., \& Schneider, A. (2014). Public Design in Global Perspective: Empirical Trends. In C. Bason (Ed.), Design for Policy (pp. 23-40). Gower Publishing.

http://libsearch.cbs.dk/primo_library/libweb/action/dlDisplay.do?docld=CBS01000688929\&vid=CBS\&a fterPDS=true

Binder, T., \& Brandt, E. (2008). The Design:Lab as platform in participatory design research. CoDesign, 4(2), 115129. https://doi.org/10.1080/15710880802117113

Bommert, B. (2010). Collaborative innovation in the public sector. International Public Management Review, 11(1), 15-33. https://journals.sfu.ca/ipmr/index.php/ipmr/article/view/73

Brown, J., \& Isaacs, D. (2006). The world café: Shaping our futures through conversations that matter. BerrettKoehler.

Considine, M., Alexander, D., \& Lewis, J. M. (2014). Policy design as craft: Teasing out policy design expertise using a semi-experimental approach. Policy Sciences, 47(3), 209-225. https://doi.org/10.1007/s11077013-9191-0

Corrigan, C. (2015). Hosting and holding dialogic containers. In Gervase Bushe, Robert J. Marshak (Ed.), Dialogic organization development: The theory and practice of transformational change (pp. 291-304). BerrettKoehler Publishers.

Corrigan, C. (2016). Hosting dialogic containers: A key to working with complexity. OD Practitioner, 48(2), 30-35. http://www.chriscorrigan.com/parkinglot/wp-content/uploads/2008/08/ODP-V48No2Corrigan_Rev3.pdf

Covey, S. M. R., \& Merrill, R. R. (2006). The speed of trust: The one thing that changes everything. Free Press.

Drimie, S., Hamann, R., Manderson, A., \& Mlondobozi, N. (2018). Creating transformative spaces for dialogue and action: Reflecting on the experience of the Southern Africa Food Lab. Ecology and Society, 23(3). https://doi.org/10.5751/ES-10177-230302

Government of New Brunswick. (2017). New Brunswick labour market outlook 2017-2026. NB Jobs. https://www.nbjobs.ca/sites/default/files/pdf/nblmo-final_e.pdf

Gryszkiewicz, L., Lykourentzou, I., \& Toivonen, T. (2016). Innovation Labs: Leveraging Openness for Radical Innovation? (SSRN Scholarly Paper ID 2556692). Social Science Research Network. https://papers.ssrn.com/abstract=2556692

Hassan, Z. (2014). The social labs revolution: A new approach to solving our most complex challenges. BerrettKoehler Publishers.

Jones, P. H. (2014). Systemic design principles for complex social systems. In G. S. Metcalf (Ed.), Social systems and design (pp. 91-128). Springer. https://doi.org/10.1007/978-4-431-54478-4_4

Jones, R. (2018, February 12). N.B. economic growth expected to be worst of 10 provinces in 2018. CBC News. http://www.cbc.ca/news/canada/new-brunswick/economic-growth-worst-among-provinces-20181.4530882

Lichtenstein, B. B. (2014). Generative emergence: A new discipline of organizational, entrepreneurial, and social innovation. Oxford Scholarship.

http://www.oxfordscholarship.com/view/10.1093/acprof:oso/9780199933594.001.0001/acprof9780199933594

McGann, M., Blomkamp, E. \& Lewis, J.M. (2018). The rise of public sector innovation labs: experiments in design thinking for policy. Policy Sciences 51(3), 249-267. https://doi.org/10.1007/s11077-018-9315-7 
Moore, M.-L., P. Olsson, W. Nilsson, L. Rose, and F. R. Westley. 2018. Navigating emergence and system reflexivity as key transformative capacities: experiences from a Global Fellowship program. Ecology and Society 23(2):38. https://doi.org/10.5751/ES-10166-230238

Muthukumaran, R. (2018). NEW BRUNSWICK - Slower pace ahead. Royal Bank of Canada. https://edgsj.com/storage/pdfs/resources/PFrMpb8kKpkdQw40822Cf71WDjMSXzzDoL8eV9bl.pdf

Nesta. (2019). Competency framework for experimenting and public problem solving. https://www.nesta.org.uk/toolkit/skills-attitudes-and-behaviours-fuel-public-innovation/

Newman, G. E., Bloom, P., \& Knobe, J. (2014). Value judgments and the true self. Personality and Social Psychology Bulletin, 40(2), 203-216. https://doi.org/10.1177/0146167213508791

NouLAB. (2018). Economic Immigration Lab: Impact report and year in review. https://docs.wixstatic.com/ugd/e07719_5433596252a54b178056b8a34dc51231.pdf

Owen, H. (2008). Wave Rider: Leadership for high performance in a self-organizing world. Berrett-Koehler Publishers.

Public Policy Forum. (2018). The people imperative: Come from away and stay: Strategies to grow population and prosperity in Atlantic Canada. https://ppforum.ca/wp-content/uploads/2018/03/PPF-The-PeopleImperative-Vol1-Digital.pdf

Quick, K., \& Sandfort, J. (2014). Learning to facilitate deliberation: Practicing the art of hosting. Critical Policy Studies, 8(3), 300-322. https://doi.org/10.1080/19460171.2014.912959

Quick, K., Sandfort, J., \& Stuber, N. (2012). Practicing the Art of Hosting: Exploring what Art of Hosting and Harvesting workshop participants understand and do. https://doi.org/10.13140/2.1.2676.8161

Ryan, A. J. (2014). A framework for systemic design. FORMakademisk, 7(4), 1-14. https://doi.org/10.7577/formakademisk.787

Scharmer, C. O., \& Kaeufer, K. (2010). In front of the blank canvas: Sensing emerging futures. Journal of Business Strategy, 31(4), 21-29. https://doi.org/10.1108/02756661011055159

Senge, P. M., Scharmer, C. O., Jaworski, J., \& Flowers, B. S. (2005). Presence: An exploration of profound change in people, organizations, and society. Crown Publishing Group.

Tõnurist, P., Kattel, R., \& Lember, V. (2015). Discovering Innovation Labs in the Public Sector (No. 61; The Other Canon Foundation and Tallinn University of Technology Working Papers in Technology Governance and Economic Dynamics). TUT Ragnar Nurkse Department of Innovation and Governance. https://ideas.repec.org/p/tth/wpaper/61.html

Tõnurist, P., Kattel, R., \& Lember, V. (2017). Innovation labs in the public sector: What they are and what they do? Public Management Review. https://doi.org/10.1080/14719037.2017.1287939

Torfing, J. (2019). Collaborative innovation in the public sector: The argument. Public Management Review, 21(1), 1-11. https://doi.org/10.1080/14719037.2018.1430248

Transition US. (2013). The fourfold practice. http://www.transitionus.org/sites/default/files/The\%20Fourfold\%20Practice.pdf

Valkenburg, R., \& Dorst, K. (1998). The reflective practice of design teams. Design Studies, 19(3), $249-271$. https://doi.org/10.1016/S0142-694X(98)00011-8

Van der Merwe, E. S., Biggs, R., Preiser, R., Cunningham, C., Snowden, J. D., O’Brien, K., Jenal, M., Vosloo, M., Blignaut, S., \& Goh, Z. (2019). Making Sense of Complexity: Using SenseMaker as a Research Tool. Systems, 7(2). https://doi.org/10.3390/systems7020025

Voorberg, W. H., Bekkers, V. J. J. M., \& Tummers, L. G. (2015). A Systematic Review of Co-Creation and CoProduction: Embarking on the social innovation journey. Public Management Review, 17(9), 13331357. https://doi.org/10.1080/14719037.2014.930505 
Westley, F., Laban, S., Rose, C., McGowan, K., Robinson, K., Tjornbo, O., \& Tovey, M. (2015). Social innovation lab guide. Rockefeller Foundation. https://uwaterloo.ca/waterloo-institute-for-social-innovation-andresilience/sites/ca.waterloo-institute-for-social-innovation-andresilience/files/uploads/files/10_silabguide_final.pdf

World Café Community Foundation. (2015). Cafe to Go: A Quick Reference Guide for Hosting World Café. http://www.theworldcafe.com/wp-content/uploads/2015/07/Cafe-To-Go-Revised.pdf 